NBER WORKING PAPER SERIES

\author{
ENTRY AND EXIT, PRODUCT \\ VARIETY AND THE BUSINESS CYCLE
}

Satyajit Chatterjee

Russell W. Cooper

Working Paper No. 4562

\author{
NATIONAL BUREAU OF ECONOMIC RESEARCH \\ 1050 Massachusetts Avenue \\ Cambridge, MA 02138 \\ December, 1993
}

We are grateful to Paul Beaudry, Jean-Pascal Benassy, John Fender, John Haltiwanger, Andreas Hornstein, Sam Kortum, Richard Rogerson and Avi Simhony as well as participants at seminars at the Board of Governors of the Federal Reserve System, the 1992 Econometric Society Meeting, the Federal Reserve Bank of Minneapolis, the Hebrew University, the NBER Macroeconomics Lunch, the 1993 NBER Summer Institute, New York University, Tel Aviv University, the University of Pennsylvania and the University of Warwick for helpful discussions about this research. We are grateful to Alok Johri for research assistance. The second author thanks the National Science Foundation for financial support. The views expressed herein are solely those of the authors and do not necessarily reflect the views of the Federal Reserve Bank of Philadelphia, the Federal Reserve System, or the National Bureau of Economic Research. This paper is part of NBER's research program in Economic Fluctuations. 


\title{
ENTRY AND EXIT, PRODUCT \\ VARIETY AND THE BUSINESS CYCLE
}

\begin{abstract}
We study the stochastic behavior of a dynamic general equilibrium model with monopolistic competition. Each seller sells his product in the consumption goods as well as the investment goods market and has market power in both. Consumers derive utility from a CES aggregate of all the consumption goods and augment their capital stock by a CES aggregate of all the investment goods. We analyze the equilibrium of this economy allowing for an endogenous determination of the number of firms and therefore of products. The principal effect we highlight is the endogenous propagation and magnification of technology and preference disturbances through product space variations.
\end{abstract}

Satyajit Chatterjee Research Department

Federal Reserve Bank of Philadelphia Philadelphia, PA 19106

\author{
Russell W. Cooper \\ Department of Economics \\ Boston University \\ Boston, MA 02215 \\ and NBER
}


"Entry and Exit, Product Variety and the Business Cycle"•

\section{Introduction}

Microeconomic measurements provide evidence of substantial markups of price over marginal cost in many industries (see Domowitz, Hubbard and Peterson [1988] and Hall [1988]). It is not uncommon to find estimates of markups that are in excess of 2.0 . In contrast, macroeconomic models typically assume perfect competition. Is this disparity between facts and theoretical modelling quantitatively important? The purpose of this project is to assess this question in the context of a numerically specified neoclassical growth model modified to include monopolistic competition. We focus on two issues: first, how the existence of imperfect competition magnifies disturbances to technology and preferences and second, how it affects the propagation of these disturbances over time.

Our main finding can be summarized as follows. When we allow the number of firms to vary in response to exogenous disturbances, i.e. allow the entry and exit of firms, then the effects of markups can be very significant. In particular, there is considerable magnification and propagation of exogenous disturbances. This interaction between entry and exit and markups comes from the fact that markups exist because firms produce goods that are imperfect substitutes for each other. Therefore, as the number of firms increases the diversity of the product space increases as well and that encourages agents to work harder and accumulate more capital. In other words, more entry encourages more effort and accumulation which in turn encourages more entry in the current and future periods. This positive feedback in entry decisions underlies the magnification and propagation of exogenous shocks. Without entry and exit, the product diversity effects implicit in industry markups is 
left unrealized. While our analysis mainly focuses on the propagation of technology shocks, the mechanism of product variation that we highlight could be operative in environments in which the initial impulse is from other sources, such as credit market conditions.

Therefore, in addition to markups our framework also emphasizes the role of entry and exit of firms in business fluctuations. This emphasis is not misplaced. Figure 1 plots detrended real gross national product and detrended net business formation at the quarterly frequency from 1955:1 to $1983: 4 .^{1}$ The contemporaneous correlation between these two variables is about .54 . Generally, net business formation is quite low during economic downturns due to the increase in business failures. This was certainly true during the period of the Great Depression years. The number of firms in all industries fell about $10 \%$ from 1929 to 1933. In manufacturing, the fall was in excess of $33 \%$ and the number of manufacturing firms did not return to its 1929 level until $1945 .^{2}$

Related to this evidence on the cyclical properties of net business formation are the findings on job creation and job destruction due to the births and deaths of plants. This is important in that the net business formation data reported above concerns the births and deaths of firms not jobs. Davis-Haltiwanger [1992] find that deaths constituted about $25 \%$ of overall job destruction while births contributed about $20 \%$ of job creation for the $1972-86$ period. While these are not cyclical numbers, they do point to the role of variations in the number of firms for understanding overall job creation and job destruction. Over the cycle

\footnotetext{
1 A linear trend was removed from both of these series, both of which are available in the Economic Report of the President. The series end in 1983 due to a change in methodology for computing the net business formation index.

2 This evidence is from Dun \& Bradstreet Reference Book and Failure Statistics reported in U.S. Department of Commerce [1975].
} 


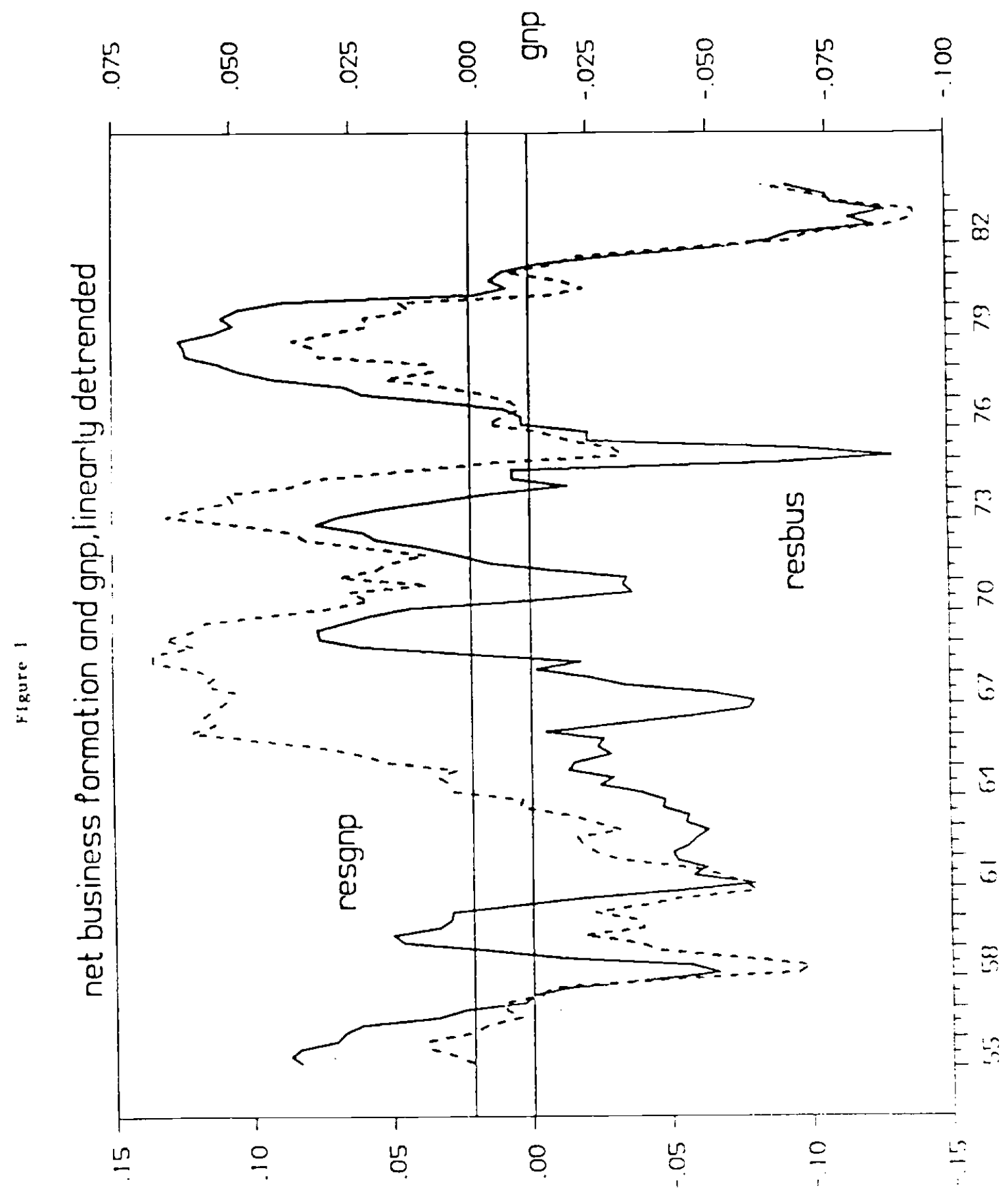


we find that plant deaths are an important component of job destruction. For example, from 1980 to 1983 overall job destruction rates rose from 8.1 to $13.6 \%$ while job destruction rates from plant deaths rose by much more, from .9 to $3.6 \% .^{3}$ The contribution of deaths to job destruction appears across sectors of the economy.

Linking variations in the number of firms to product space variations is much more difficult as we have no direct measures of the size of the product space. Instead we use variations in the number of firms as a proxy. To the extent that there are product space variations without changes in the number of firms, due to multi-product firms, this will understate product space variations. For example, Jovanovic [1993] studies product diversification by firms and argues that firm size and product diversification move together empirically, leading to product space expansions during upturns. Second, new entrants might be producing products which are substitutes for existing products so that entry creates no apparent product space variation at all. However, we consider location to be an important element in the definition of a product, as well as a source of market power, so that new firms must be providing a differentiated product. The extent of that differentiation will be measured once we calibrate our model.

Our paper contributes to the recent literature on the quantitative importance of imperfect competition in macroeconomic fluctuations. Rotemberg and Woodford $[1990,1991,1992]$ analyze the role of variations in markups as a cyclical shift variable in labor demand functions. They abstract from entry and exit of firms and focus on the

\footnotetext{
3 These calculations use aggregated two-digit data on job creation and job destruction supplied by John Haltiwanger for the 1973-88 period. The growth rates are calculated as the ratio of a flow (e.g. total job losses) over the stock of jobs in the previous period.
} 
strategic interactions between existing firms producing the same product. In contrast, we abstract from strategic interactions by assuming that each product is made by a single firm but focus on the impact of entry and exit of firms. An important difference entailed by this shift in emphasis is that in our model markups are constant while in Rotemberg and Woodford they are countercyclical. While Rotemberg and Woodford provide some time series evidence in support of countercyclical markups, there is counter evidence contained in other studies, such as Domowitz, Hubbard and Peterson [1988] and Galeotti and Schiantarelli [1991]. Thus, there is value to examining mechanisms that link markups to macroeconomic fluctuations without requiring them to vary over the cycle.

The assessment of the quantitative importance of imperfect competition and increasing retums has also been attempted in the real business cycle literature. Hornstein [1992] and Devereux, Head and Lapham [1992] analyze to what extent the calculation of the importance of technology shocks in GNP fluctuations is affected by the recognition of markups and different forms of increasing returns to scale. Hornstein analyzes a model similar to ours but abstracts from entry and exit and finds that the joint hypothesis of imperfect competition and increasing retums to scale does not alter the contribution of technology shocks very much. Devereux, Head and Lapham allow for entry and exit and the product diversity affect and find that technology shocks could account for even more fluctuations in GNP than the competitive model or the imperfect competition model with no entry." The latter paper is closest in spirit to ours, although there are considerable differences in modelling details and focus. In particular, our main interest is in understanding the dynamic response of the

\footnotetext{
- In their terminology, the product diversity effect is increasing returns to specialization.
} 
economy to different type of exogenous shocks rather than in evaluating the importance of technology shocks in GNP fluctuations.

The element of positive feedback in entry decisions makes our model similar to macroeconomic models with strategic complementarity arising through production externalities. Baxter-King [1991] and Klenow [1990] develop quantitative business cycle models in which a positive production externality is assumed as in the theoretical formulation of Bryant [1983]. In contrast, in our framework the analog of these technological spillovers arise endogenously as a natural consequence of the primitives of the model. As a result, the strength of the feedback is determined indirectly through the calibration of the model to micro-observation on markups (since they reveal the substitutability of goods and hence the magnitude of the product variation effect) rather than through estimates based on aggregate observations (on inputs and output) as in Baxter-King.

The paper is organized as follows. The basic model is presented in Section II and the role of the interaction between markups and entry decisions is clearly brought out. In Section III we calibrate the model and study its behavior by examining its moment properties and impulse response dynamics. We find that it can generate quantitatively significant magnification and propagation effects. Section IV concludes.

\section{Model}

This section describes the decision problems for the many firms and the single representative consumer who populate our economy. The section provides a set of necessary and sufficient conditions that an equilibrium of the economy must satisfy and uses these to 
understand how markups and entry decisions affect the marginal return to work effort and capital accumulation.

\section{II.A The Consumer}

There is a single infinitely-lived representative consumer. There are many firms in the economy, each capable of producing a unique good which can be sold either as a consumption or an investment good. ${ }^{5}$ Let $N_{1}$ denote the number of producing firms in period $t$ with $p_{c t}^{j}$ and $p_{u l}^{j}$ as the consumption and investment price of the $j$ th good, $j \in\left\{1,2, \ldots N_{t}\right\}$, measured in some abstract unit of account. The consumer derives utility from leisure and the consumption of each of the produced goods and earns income from renting labor and capital to firms. The rental price of a unit of labor time is $w_{1}$ and the rental price of a unit of capital is $q_{1}$. He is also the sole owner of all existing and potential firms so that the sum of all residual profits, denoted $\Sigma_{j} \pi_{i}^{j}$, reverts to him as well. Using standard notation, his optimization problem is given as:

\footnotetext{
s As noted earlier, our formal model associates the number of firms with the number of investment and consumptions products. Our analysis can accommodate multi-product firms as long as these divisions of the firm operate independently. So, for example, a glass product that could either be used as a consumption good or used in the investment process would be treated as the output of a single firm.
} 


$$
\begin{aligned}
& \max \sum_{t=0}^{\infty} \beta^{t} u\left(c_{t}-B_{t}, l_{t}\right) \\
& \text { s.t. } \sum_{j=1}^{N_{t}} p_{c t}^{J} c_{t}^{J}+\sum_{j=1}^{N_{t}} p_{i s}^{j} i_{t}^{j} \leq w_{t}\left(1-l_{t}\right)+q k_{t}+\sum_{j=1}^{N_{t}} \pi_{t} \\
& k_{t+1}=(1-8) k_{t}+i_{t} \\
& c_{t}=\left(\sum_{j=1}^{N_{t}} c_{t}^{v_{v}}\right)^{v}, i_{t}=\left(\sum_{j=1}^{N_{t}} i_{t}^{j_{t}}\right)^{\theta}, \quad v>1, \quad \theta>1 \\
& c_{t}-B_{t} \geq 0, \quad i_{t}^{\prime} \geq 0,1 \geq l_{t} \geq 0
\end{aligned}
$$

Note that the consumption of each of the produced goods enters the utility function through a symmetric CES aggregator with elasticity of substitution given by $\nu /(1-\nu) .^{6}$ In addition to leisure, utility in period $t$ is affected by disturbance term $B_{t}$ which affects the marginal utility of consumption relative to leisure positively.

Following Kiyotaki [1988], investment in period $t$ is assumed to be a symmetric CES aggregate with elasticity of substitution $\theta /(1-\theta)$. This assumption along with the assumption that accumulation is done by the consumer rather than firms ensures that the number of firms in period $\mathrm{t}(\mathrm{N})$ does not appear as a state variable in the following period: the only

- This specification of preferences is the same as that used in the Section 1 model of Dixit-Stiglitz [1977] though our utility function includes leisure and their specification included a numeraire good. Logically, imperfect substitutability is a necessary but not a sufficient condition for there to be a benefit from product diversity. For instance, if the CES aggregate for consumption is normalized by $N^{-(1 /(1 \cdot x)}$ where $x$ is the elasticity of substitution (e.g., Blanchard and Fisher [1989], Chpt.8), the influence of $N$ is removed from the indices. Benassy [1993] discusses an alternative specification of preferences for these models which parameterizes the "love of variety" effect and presents new results on the welfare properties of decentralized equilibria However, economic intuition suggests that imperfect substitutability and benefit from diversity are related. As a concrete example, consider the impact of a larger number of gas stations in a city. If the advertised prices are not very different across stations, drivers would tend to go into the nearest available station to fill up when the indicator turns low. In such a situation, the average distance people have to travel to fill up is lowered when there are a larger number of stations around. 
endogenous state variable in the model is the beginning-of-period capital stock $\left(k_{j}\right)$. Also, since the consumption price of a good is allowed to be different from its investment price, it is assumed that the consumer cannot transform consumption goods into investment goods or vice versa. This implies the non-negativity constraint on the purchase of investment goods in the above problem.

The use of these two separate aggregators is meant to capture the importance of diversity for consumers as well as producers without straying too far from the traditional one sector model. ${ }^{7}$ This specification allows us to capture imperfect substitutability within consumer goods as distinct from the degree of substitutability of inputs into the investment process. From the consumer's side, the CES function represents a home production function in which consumption goods purchased in period $t$ are used to produce a consumption aggregate, $c_{1}$. Similarly, the consumer purchases a variety of investment goods which are combined to produce additional capital in the following period. In the process of producing capital, an increase in product variety increases the marginal efficiency of investment of each good available in the economy. As shown below, for both of these production processes, the cost of producing a unit of output (consumption or investment) falls as the number of products available to the consumer increases. Of course, the magnitudes of these "benefit of variety" effects are governed by the parameters $\nu$ and $\theta$.

Given $c_{t}$ and $i_{t}$, the consumption and investment demand for good $j$ in period $t$ is given by:

\footnotetext{
1 Our model can be viewed as an aggregate model in which the degree of substitutability between products in different sectors is the same for every pair of sectors. An altemative would model the interaction between firms within sectors in a multi-sector economy and thus allow for richer substitutability across goods.
} 


$$
c_{t}^{J}=c_{t}\left(\frac{p_{c t}^{J}}{p_{c t}}\right)^{\frac{v}{1-v}}, \quad i_{t}^{J}=i_{t}\left(\frac{p_{i t}^{J}}{p_{i t}}\right)^{\frac{\theta}{1-\theta}} .
$$

where $\mathrm{p}_{\mathrm{ct}}$ and $\mathrm{p}_{\mathrm{it}}$ are price indices given by:

$$
p_{c t}=\left(\sum_{j=1}^{N_{t}}\left(p_{c j}^{j}\right)^{\frac{1}{1-\nu}}\right)^{1-\nu}, \quad p_{i t}=\left(\sum_{j=1}^{N_{t}}\left(p_{i j}^{j}\right)^{\frac{1}{1-\theta}}\right)^{1-\theta}
$$

These price indices show the benefit from variety effects: if the price of all types of consumption (investment) goods is the same, then, since $\nu$ and $\theta$ exceed 1 , the consumption (investment) price index is a decreasing function of $\mathrm{N}_{\mathrm{r}}$. Therefore, an increase in the number of products lowers the cost of consumption and investment relative to leisure. If $\nu \neq \theta$, an increase in $\mathrm{N}_{\mathrm{t}}$ also alters the cost of the consumption good relative to the investment good; in particular it falls if $\nu<\theta$. Intuitively, these effects arise because the produced goods are imperfect substitutes for each other. As more of them become available it becomes easier (i.e. cheaper) to satisfy a given level of demand. Note that the strength of these effects depend on the degree to which $\nu$ or $\theta$ depart from 1; the number of firms has no effect on the price indices when $\nu$ and $\theta$ are 1, i.e, the goods are perfect substitutes for each other.

The "love of variety" effect emphasized here also appears in models of location (e.g. Ciccone-Hall [1993] and the references therein) assuming that some goods are not costlessly transportable. Further, as in Shea [1993], these same effects can underlie the linkages that create positive comovement in output and employment across industries. A good example concerns automobile plants and their upstream suppliers, as described in Cooper-Haltiwanger [1993]. During the interwar years, there were sizable seasonal variations in the production 
of automobile plants. The upstream suppliers of these plants, who were located quite close by, had dramatic seasonal fluctuations as well. Further, the business failures that occured during this period led to a reduction in suppliers and, from our perspective, a contraction of the product space. So, the product space variations that we emphasize here are just one manifestation of the forces that underlie temporal and spatial agglomeration.

Using the price indices noted in (2), the budget constraint in the consumer's problem can be compactly written as:

$$
p_{c t} c_{t}+p_{i t} i_{t} \leq w_{t}\left(1-l_{t}\right)+q_{t} k_{t}+\sum_{j=1}^{N_{t}} \pi_{t}
$$

Thus, ignoring non-negativity constraints, the intratemporal and intertemporal efficiency conditions are:

$$
\begin{gathered}
\frac{u_{d}\left(c_{t}, l_{t}\right)}{u_{c}\left(c_{t}, l\right)}=\frac{w_{t}}{p_{c t}} \\
u_{c}\left(c_{t}, l_{t}\right)\left(\frac{p_{i t}}{p_{c t}}\right)=\beta u_{c}\left(c_{t+1}, l_{t+1}\right)\left(\frac{q_{t+1}}{p_{c t+1}}+(1-8) \frac{p_{t t+1}}{p_{c t+1}}\right)
\end{gathered}
$$

The Euler equation, given by (5), says that the consumer's loss from reducing the consumption index by a unit in period $t$, purchasing some of the investment index equals the gain obtained by consuming the proceeds from first renting the capital and then selling the undepreciated capital in the following period. In addition, the transversality condition on capital stock is satisfied if: 


$$
\lim _{t \rightarrow \infty} \beta^{t} u_{c}\left(c_{t}, l_{t}\right) k_{t+1}=0
$$

\section{B Firms}

Each of the $N_{t}$ firms active in the economy in period t produces a single, unique good. Good j, produced by seller $\mathrm{j}$, can either be sold to consumers as a consumption good (at a price $\mathrm{p}_{\mathrm{s}}^{j}$ ) or as an investment good (at a price $\mathrm{p}_{i}^{j}$ ). Thus, we assume that the firm can price discriminate between consumption and investment goods markets.

Since the capital accumulation decision is made by the consumer, each firm needs to solve a static profit maximization problem. Each firm takes factor prices as given but recognizes its market power in the commodity market; i.e., on the output side it takes the demand curve (rather than price) as given. Production proceeds up to the point where the marginal cost of producing a unit of the good is equal to the marginal revenue in each market. Any profit from this endeavor is distributed to the consumer.

Formally, each firm solves:

$$
\begin{array}{ll}
\max & \pi_{t}^{j}=p_{c t}^{j} s_{c t}^{j}+p_{i t}^{j} s_{i t}^{j}-q_{t} k_{t}^{j}-w_{t} n_{t}^{J} \\
\text { s.t. } & s_{c t}^{j}+s_{i t}^{j} \leq A_{t} F\left(n_{t}^{j}-\bar{n}, k_{t}^{j}-\bar{k}\right)
\end{array}
$$

where $s_{\mathrm{si}}^{j}$ and $s_{i b}^{j}$ are the $j$ th firm's sale of consumption and investment goods. The production function $F(.,$.$) is characterized by overhead labor (\vec{n})$ and overhead capital $(k)$. The overhead costs are important to our analysis because we wish to reconcile the existence of market

- Gali [1992], in contrast, assumes that such price discrimination is impossible. Thus the optimal price of a seller reflects a weighted average of the degree of substitutability between consumption goods and the degree of substitutability between investment goods. Thus variations in the markup arise from changes in the composition of output between consumption and investment. These compositional effects on the markup are absent bere. 
power with no excessive profits on average. 'The technology parameter $A_{t}$ (along with the preference parameter $B_{V}$ ) will be a source of fluctuations in the economy. ${ }^{10}$

The demand functions in (1) can be inverted to give the inverse demand functions facing firm $j$ in the consumption and investment markets:

$$
p_{c t}^{J}=\left(\frac{s_{c t}^{J}}{c_{t}}\right)^{\frac{1-v}{v}} p_{c t}, \quad p_{i t}^{j}=\left(\frac{s_{i t}^{j}}{i_{t}}\right)^{\frac{1-\theta}{\theta}} p_{i t}
$$

It is assumed that $N_{1}$ is large so that each firm takes the aggregate consumption and investment $\left(c_{1}\right.$ and $\left.i_{i}\right)$ and the price indices $\left(p_{c t}\right.$ and $\left.p_{i l}\right)$ as given. In other words, these economy-wide variables determine the position of each firm's demand functions. It follows that the marginal revenue in each of these markets is simply $p_{s i}^{j} / \nu$ and $p_{i l}^{j} / \theta$. Therefore, the first-order necessary conditions for the jth firm's optimization problem can be compactly written as:

$$
\begin{gathered}
\frac{p_{c t}^{J}\left(s_{c t}^{J}\right)}{v}=\frac{p_{i t}^{J}\left(A F\left(n_{t}^{j}-\bar{n}, k_{t}^{j}-\bar{k}\right)-s_{c t}^{J}\right)}{\theta} \\
A_{t} \frac{F_{n}\left(n_{t}^{j}-\bar{n}, k_{t}^{j}-\bar{k}\right)}{v}=\frac{w_{t}}{p_{c t}^{j}}
\end{gathered}
$$

9 Rotemberg and Woodford [1990] use a similar motivation for the introduction of overbead labor.

10 Here we abstract from deterministic growth. As in King,Plosser and Rebelo [1988], deterministic labor augmenting progress could be added to the model. The economy would then be made stationary by "dividing through" by the state of labor productivity without any influence on the results we report here. One implication of allowing this type of growth would be that the overhead labor and capital costs would also increase over time at the same rate as labor productivity. As a consequence, there would be no vasiation in the number of products produced, though as in Stokey [1988], the spectrum of products produced might change over time. 


$$
A_{t} \frac{F_{k}\left(n_{t}^{j}-\bar{n}, k_{t}^{j}-\bar{k}\right)}{v}=\frac{q_{t}}{p_{c t}^{j}}
$$

Condition (8) implies that the marginal revenue from the sale of output as a consumption

good equals that from the sale of output as investment. Conditions (9) and (10) are the usual markup equations when output is sold as consumption. Using (8), these can be rewritten for the case of output being sold as investment. These conditions are used in the calibration of the model as they provide the link between the markups and the degree of substitutability across consumption and investment goods. Using these conditions, the $j^{\text {th }}$ firm's profits in period $t$ is:

$$
\pi_{t}^{j}=p_{c t}^{j}\left\{s_{c t}^{j}+\left(\frac{\theta}{v}\right)\left(A_{t} F-s_{c t}^{j}\right)-A\left(\left(\frac{F_{n}}{v}\right) n_{t}^{j}+\left(\frac{F_{k}}{v}\right) k_{t}^{j}\right)\right\}
$$

At the optimum, it is required that $\pi_{\mathfrak{t}}^{j} \geq 0$.

II. C Equilibrium Conditions

Since the output of each active firm appears symmetrically in the consumption and investment aggregate, the equilibrium quantity and price of each good will be the same. Also, since prices are in an abstract unit of account, we can set $p_{c t}^{j}$ to 1 for all $t$ (and $j$ ) without any loss of generality. Then, a set of sequences $\left\{c_{t}\right\}_{0}^{\infty},\left\{n_{t}\right\}_{0}^{\infty},\left\{k_{t}\right\}_{0}^{\infty},\left\{N_{t}\right\}_{0}^{\infty},\left\{p_{i 1}^{j}\right\}_{0}^{\infty}$, $\left\{w_{1}\right\}_{0}^{\infty}$, and $\left\{q_{1}\right\}_{0}^{\infty}$ constitutes a perfect foresight, symmetric, and monopolistically competitive equilibrium if they satisfy (3)-(6) and the sequences $\left\{s_{c 1}^{j}=c_{t} / N_{i}^{j}\right\}_{0}^{\infty},\left\{s_{11}^{j}=\left(k_{1+1}-(1-\delta) k_{v} / N_{1}^{o}\right\}_{0}^{\infty}\right.$, $\left\{n_{\mathrm{t}}^{j}=n_{\mathrm{t}} / N_{\mathrm{l}}\right\}_{0}^{\infty}$, and $\left\{\mathrm{k}_{\mathrm{i}}^{\mathrm{j}}=\mathrm{k}_{\mathrm{l}} / \mathrm{N}_{\mathrm{l}}\right\}_{0}^{\infty}$ satisfy (8) $-(10)$ with $\pi_{\mathrm{t}}^{\mathrm{i}}$ in (11) equal to zero.

The conditions for consumer and firm optimization can be used to eliminate the price, 
wage and capital-rental terms. Also, homogeneity of degree 1 implies that $F\left(n_{l} / N_{l}-\bar{n}, k_{l} / N_{i^{-}}\right.$ $\bar{k})$ is identical to $F\left(n_{l}-N_{1} \bar{n}, k_{1}-N_{1} \bar{k}\right)$ and $F_{x}\left(n_{l} / N_{1}-\bar{n}, k_{l} / N_{1}-\bar{k}\right)=F_{x}\left(n_{1}-N_{1} \bar{n}, k_{1}-N_{1} \bar{k}\right)$ for $x=$ $n, k$. Therefore, the conditions of equilibrium reduce to the following five equations:

$$
\begin{gathered}
\frac{u_{t}\left(c_{p} 1-n_{t}\right)}{u_{c}\left(c_{p} 1-n_{t}\right)}=A_{t} N_{t}^{v-1} \frac{F_{n}\left(n_{t}-N_{t} \bar{n}, k_{t}-N_{t} \bar{k}\right)}{v} \\
u_{c}\left(c_{t}, 1-n_{t}\right) \frac{\theta}{v} N_{t}^{v-\theta}= \\
\beta u_{c}\left(c_{t+1}, 1-n_{t+1}\right)\left\{A_{t+1} N_{t+1}^{v-1} \frac{F_{k}\left(n_{t+1}-N_{t+1} \bar{n}, k_{t+1}-N_{t+1} \bar{k}\right)}{v}+(1-\delta) \frac{\theta}{v} N_{t+1}^{v-\theta}\right\} \\
c_{t}+\frac{\theta}{v} N_{t}^{v-\theta}\left\{k_{t+1}-(1-\delta) k_{t}\right\} \\
=A_{t}^{v-\theta}\left\{N_{t}^{v-1}\left\{\frac{F_{n}\left(n_{t}-N_{t} \bar{n}, k_{t}-N \bar{k}\right)}{v} n_{t}+\frac{F_{k}\left(n_{t}-N_{t} \bar{n}, k_{t}-N \bar{k}\right)}{v} k_{t}\right\}\right. \\
\lim _{t-\infty} \beta^{t} u_{c}\left(c_{t}, n_{t}\right) k_{t+1}=0
\end{gathered}
$$

The first two are the familiar intratemporal and intertemporal efficiency conditions. The third equation is the resource balance condition for the firm (i.e., the constraint in the optimization problem of the firm) expressed in terms of economy-wide variables. The fourth condition is the zero profit condition of firms also expressed in terms of economy-wide variables. The final equation is the transversality condition.

\section{II.D The Role of Markups and Entry and Exit}


The objective of our study is to examine how the existence of market power in product markets affects the economy's response to exogenous variation in preferences and technology. Equations (12)-(15) give us qualitative insight into this question. Here we discuss these themes and return to them in our discussion of the quantitative properties of the model.

To begin with, a useful feature of these equations is that they nest the basic perfectly competitive neoclassical macroeconomic model analyzed in King, Plosser and Rebelo [1988]. This basic model corresponds to the case where $\nu=\theta=1$ and $\bar{n}=\bar{k}=0$. If we assume, for the moment that $\nu=\theta$, then the model with imperfect competition differs in three important respects from the basic neoclassical model.

First, the total factor productivity term $A_{t}$ in the basic model is replaced by the composite term $A_{1} N_{1}^{-1}$ on the right hand side of (12)-(15). Since $N_{1}$ is an endogenous variable, the effective total factor productivity in our model is endogenous and positively related to $\mathrm{N}_{1}$ since $\nu>1$.

Intuitively, we would expect an increase in $A_{1}$ to increase the equilibrium number of firms in period $t$ so that a given exogenous shock to productivity would be larger in the imperfectly competitive model than in the competitive model; i.e, the imperfectly competitive model magnifies the impact of productivity disturbances. In fact, if this was a static economy, the condition for intratemporal optimization, (12), indicates that employment would respond to the variations in $\mathrm{A}_{1} \mathrm{~N}_{\mathrm{i}}^{r-1}$ through the usual static labor supply response. So, the static response to changes in $A_{1}$ would depend on the response of the number of firms to $A_{t}$, the degree of product substitutability $(\nu)$ and the elasticity of labor supply. In a 
dynamic setting, the relevant part of the employment response is the degree of intertemporal substitution so that the magnification effect should be larger the more elastic is labor supply and the less permanent is the shock.

An increase in total effective factor productivity in period t would also encourage more accumulation of capital which in turn increases the number of firms in future periods. Therefore, even if the original shock to $A_{1}$ is purely temporary, effective factor productivity will be serially correlated; i.e., the imperfectly competitive model provides additional propagation of productivity disturbances.

Variations in $B_{1}$ increase the desire for consumption relative to leisure and thus increase the demand for the consumption relative to investment. With a fixed product space, this leads to a negative correlation between investment and consumption. However, if the overall effect of this taste shock is to increase the number of firms, the economy could generate a correlated increase in effective productivity leading to a positive correlation in consumption and investment. Similar effects are described by Baxter-King [1991] in a model with production externalities.

A second important aspect of introducing imperfect competition is that the presence of overhead labor and overhead capital influences the responsiveness of the economy to underlying shocks. As discussed in Hornstein [1992] as well, the key to understanding the effects of monopolistic competition (leaving aside product space variations through entry and exit) concerns the introduction of overhead costs, which are needed to absorb the profits from markups. To see this, consider a static model in which the production function for a firm is $A(n-\bar{n})^{\alpha}$, where A represents the current state of technology. It is easy to show that 
the elasticity of labor demand with respect to A, holding the real wage constant, is a decreasing function of the ratio of overhead to non-overhead labor. ${ }^{11}$ Therefore, the presence of overhead labor implied by the markups leads to a dampening of the response of labor demand to variations in the state of technology. This, in tum, implies that productivity is more volatile since there is less movement along (relative to shifts of) the production function.

Third, the overhead costs also have implications for the cyclical behavior of employment and capital per firm. To see this, consider the case in which $\theta=\nu$ and assume, as we will below, that the production function is Cobb-Douglas where the coefficient for labor is $\alpha$. In this case, the zero profit condition can be rewritten as:

$$
(v-1)=\frac{\alpha \bar{n}}{\left(n_{t} / N_{\imath}\right)-\bar{n}}+\frac{(1-\alpha) \bar{k}}{\left(k_{t} / N_{\imath}\right)-\bar{k}} .
$$

Hence, changes in $A_{1}$ or $B_{1}$ imply that capital per firm and the hours per firm must vary in opposite directions. If there was no overhead capital, then zero profits would imply that the number of labor hours per firm would be constant. With two types of overhead factors, labor hours per firm can vary with the state of technology. When a shock occurs which leads to the expansion of the number of products, (19) implies that the number of workers per firm must increase as well. However, as we shall see in our quantitative analysis, the correlation of GNP with labor hours per firm will depend on the persistence of the shock since over time there are variations in the capital stock.

\footnotetext{
$"$ To be precise, the elasticity of labor demand with respect to $A$ is $(1-n / n) /(1-\alpha)$.
} 


\section{Quantitative Properties}

\section{III.A. Approach}

Our goal in this section is understand the effects of net business formation, acting through product variation, on aggregate fluctuations. While the workings of this model is transparent in simple static settings, we need a numerical approach to better evaluate its dynamics. To this end, we adopt the approach of King,Plosser and Rebelo [1988] and consider a log linear approximation of the system given by (12)-(16) around the steady state. $^{12}$ Since our approach mimics that of King, Plosser and Rebelo, the reader is referred to that paper for detailed discussion of the procedure. Solving the dynamical system gives values for the state variable $\left(k_{0}\right)$ and the co-state variable as a function of the exogenously given path of the technology and preference parameters. ${ }^{13}$ Moving from this system to the stochastic economy requires a certainty equivalence assumption. That is, as in King, Plosser and Rebelo, the values of $\left\{A_{1}\right\}$ and $\left\{B_{1}\right\}$ in the dynamical system are replaced by conditional expectations and $A_{1}$ and $B_{1}$ are added as state variables. Otherwise, all equations remain unchanged.

To perform the numerical analysis, we need to specify functional forms. Again,

12 In the experiments we have conducted so far, saddle path stability holds. Recent work by BenhabibFarmer [1992] does indicate that for some parameterizations of models of monopolistic competition, the steady state may become a sink admitting the possibility of sunspot equilibria, as explored by Farmer-Guo [1992]. Further, there is the possibility of multiple steady state equilibria in this economy, as indicated by Gali [1993] for a closely related environment. Our analysis focuses on the behavior of the economy in the neighborhood of a steady state and does not allow for variations of the economy from the neighborhood of one steady state to another.

13 While our analysis has emphasized the behavior of capital in excess of the aggregate stock of overbead capital, it is important to remember that the state variable for the system is the aggregate stock of capital, some of which is used as overhead capital. The predetermined nature of the capital stock thus limits entry, particularly when overhead capital requirements are large. 
following the arguments of King,Plosser and Rebelo [1988], the functions are chosen to be consistent with lower frequency evidence on factor shares and the lack of a trend in either per capita labor hours or real interest rates. In particular, we adopt a Cobb-Douglas specification for the production function (where the inputs are labor and capital in excess of the overhead levels) and assume initially that preferences over consumption and leisure are given by $\log \left(c_{1}\right)+\log (1)$. This specification of preferences, as noted above, implies that permanent changes in the real wage will have no effect on labor supply. Variations in hours worked thus emerge solely from intertemporal substitution in response to temporary changes in the real wage (brought about by technology shocks that influence both the marginal product of labor and the spectrum of goods offered in equilibrium) or preference parameters.

In keeping with our goal, we experiment with different magnitudes of markups and overhead costs to understand the effects of these parameter variations on the magnification and propagation of temporary shocks to the system. In addition, we relate the magnitude of the movement in net business formation in the model to that observed in the U.S. data so that there is an empirical assessment of the model along this key dimension.

We evaluate three different economies. One, termed "perfect competition", is an economy close to that studied in King,Plosser and Rebelo. ${ }^{14}$ This is a standard real business cycle model with perfect competition.

Our second economy introduces monopolistic competition without allowing for

14 Specifically, $\beta=.988$, delta $=.025$ and labor's share $=.64$. In addition, we impose constant returns to scale for these simulations. Finally, the serial correlation in the technology shock, $\Phi$, was set at 9 unless stated otherwise. This is basically the parameterization that King, Plosser and Rebelo call their baseline though we do not have the underlying $4 \%$ growth in labor augmenting technological progress that they assume and their labor share is only .58 . 
product space variations through net business formation. For this exercise, called "no entry", we retain the parameterizations of the basic model but introduce markups by assuming that goods are not perfect substitutes. To parameterize the model, we set the markups and the overhead labor requirement and then solve for the overhead capital from the zero profit condition. Drawing upon Hall [1988], we set both $\theta=\nu=2$ so that the markup of price over cost is $100 \%$. Since we have no direct evidence that markups are very different between investment and consumption goods, we initially assume that these markups are equal. ${ }^{\text {is }}$ Later, as we begin to explore some of the properties of the model, we allow the markups to differ across goods. We set the ratio of production to non-production workers (a proxy for the overhead labor ratio) at 1 implying that there is one non-production worker for each production worker.

This choice of the overhead labor ratio might seem relatively high, compared to the Davis-Haitiwanger [1991] estimate of approximately $.5 .^{16}$ Further, one might think that a $100 \%$ markup is too high as well, compared to other estimates in the literature. If we adopted a more conservative estimate by reducing the markup to $30 \%$, then with an overhead labor ratio of 1 , the overhead capital ratio would be negative, which is not feasible.

15 There do not appear to be any systematic differences in Hall [1988] across sectors depending on the durability of the product. For example, the markup on durables is smaller than that for non-durables but the markup on services is even less than that for durables. The characterization of sunspot equilibria in Gali [1992], in contrast, requires differences between $v$ and $\theta$. A markup of $100 \%$ is certainly well within the range estimated by Hatl and is considered by Rotemberg-Woodford [1991] as well.

16 Note though that this estimate is oblained from the ratio of production worker hours to total hours and does not include any corrections for the possibilily that non-production workers could be more produclive than the production workers. I.e., these are not ratios of efficiency units. Once we adjust for differences across workers in the data using the data on wage differentials given in Davis-Haltiwanger [1991] the ratio of production to non-production workers is approximately .72 . This adjustment seems appropriate given that our model assumes homogenous labor. 
Reducing the overhead labor ratio to the Davis-Haltiwanger estimate of .5 and maintaining a markup of $30 \%$ implies an overhead capital ratio of only .05 , which also seems too low. We thus chose the parameter values of a $100 \%$ markup and an overhead labor ratio of 1 as a compromise which implies an overhead capital ratio of $1 .{ }^{17}$

The final economy, "entry", allows for both market power and entry and exit. The procyclical nature of profits in the no-entry treatment translates here into a positive correlation between entry and real output. This is consistent with the evidence discussed earlier that net business formation is procyclical. As noted earlier, since the evidence on the cyclical variation in markups is mixed, we focus exclusively on the effects of entry on the number of products offered in the market. For this treatment we retain the same parameter values as in the no-entry case.

The values of important parameters for these three treatments are given in Table 1. We now turn to an analysis of the properties of our model and then to an evaluation of its ability to match observations on net business formation in the U.S. economy.

\section{B. Quantitative Properties of the Model}

As mentioned already, we are interested in the magnification and propagation effects of entry and exit acting through product space variations. Impulse response dynamics provide a simple way to distinguish these two aspects.

In Figure 2, we display the path of the capital stock for the three economies when

17 The overhead capital requirement is determined in our model from the steady state zero profit condition, (19), once we have set the markups and the overhead labor ratio. The overbead capital ratio thus increases when, ceteris paribus, we raise markups. Note that we are calibrating the overhead capital and labor ratios and not the overhead capital and labor requirements directly. 

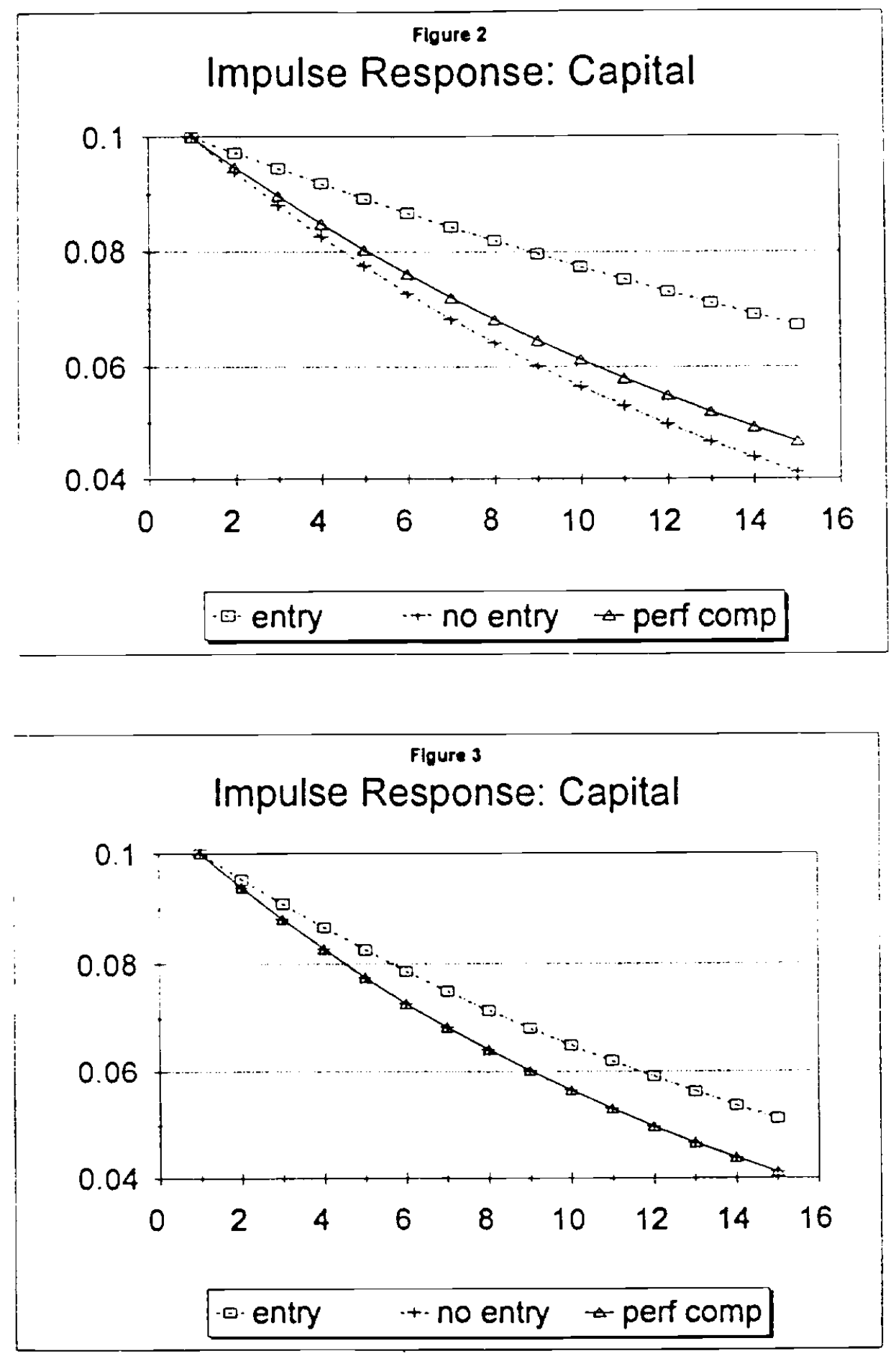
there is a ten percent increase of the stock from its steady state value. These dynamics are critical to the types of correlations produced by these economies since the speed with which the capital stock decays to its steady state controls the strength of the internal propagation mechanism of the model (see King, Plosser and Rebelo [1988] for details). Note that the propagation mechanism is strongest for the model with imperfect competition and entry and exit. In contrast, the strength of the propagation mechanism in the perfectly competitive model and the model without entry and exit are very similar with slightly more persistence in the perfectly competitive economy. In the entry treatment, an increase in the capital stock above steady state creates an incentive to entry do to the lower rental rates on capital. This product space expansion sustains a higher level of investment and hence a slower transition to the steady state.

Figure 3 shows the dynamic path of capital stock for a more conservative estimate of the markup with an elastic labor supply. ${ }^{18}$ In principle, the reduction in the markup should reduce the added propagation from variations in product variety while the more elastic labor supply will create additional propagation. Overall, the figure indicates that the propagation mechanism is now weaker but it is still significantly stronger than in the pure competitive case. Note too that here the internal propagation in the perfect competition and monopolistic competition without entry treatments is exactly the same. This is due to the elastic labor supply assumption.

We turn now to the response of the key flow variables of the model to an temporary ten percent deviation in total factor productivity. The impulse response dynanics for the

\footnotetext{
18 In this case, the markup is reduced to 1.5, the overhead capital and labor ratios are both .5 and preferences are linear in leisure, i.e. $\boldsymbol{\xi}_{\mathrm{u}}=0$.
} 
number of firms, output, consumption, investment, hours worked, productivity, and real wages are shown in Figures 4-10.19 Related correlations produced in an economy with transitory technology shocks are reported in Table 2. Throughout, $\mathrm{C}$ is the total amount of real consumption, Emp is the total level of employment (including overhead labor), Inv is the total amount of investment and Prod is average labor productivity. Hence neither $\mathrm{C}$ nor Inv conform to the CES indices used in the theoretical analysis as these indices are not measured. Instead, these measures are calculated from our model as in the National Income and Product Accounts.

As is apparent from each of the impulse responses, the imperfectly competitive model with entry and exit is substantially more responsive than either the model without entry and exit or the competitive model. These responses can be explained by relating them to the impulse response of the number of firms in the economy, indicated in Figure 4. As conjectured in the previous section, the number of firms responds positively to the productivity shock and remains elevated for a considerable length of time. Through this product diversity effect, the productivity of labor time is enhanced and output and hours worked is higher than in the competitive model. Because there is a greater variety of goods available in the economy, the consumption index can increase even though overall expenditure on consumption goods is lower. As a result, investment responds much more in our model than in the competitive one. Indeed, the greater response of investment, coupled with the slower decay of the capital stock noted earlier, provides the resources

\footnotetext{
${ }^{19}$ Note that the real wage as measured here is nominal wage deflated by producer's consumption goods prices. There is another measure of the real wage which is relevant for consumers which deflates the nominal wage by the CES price index.
} 

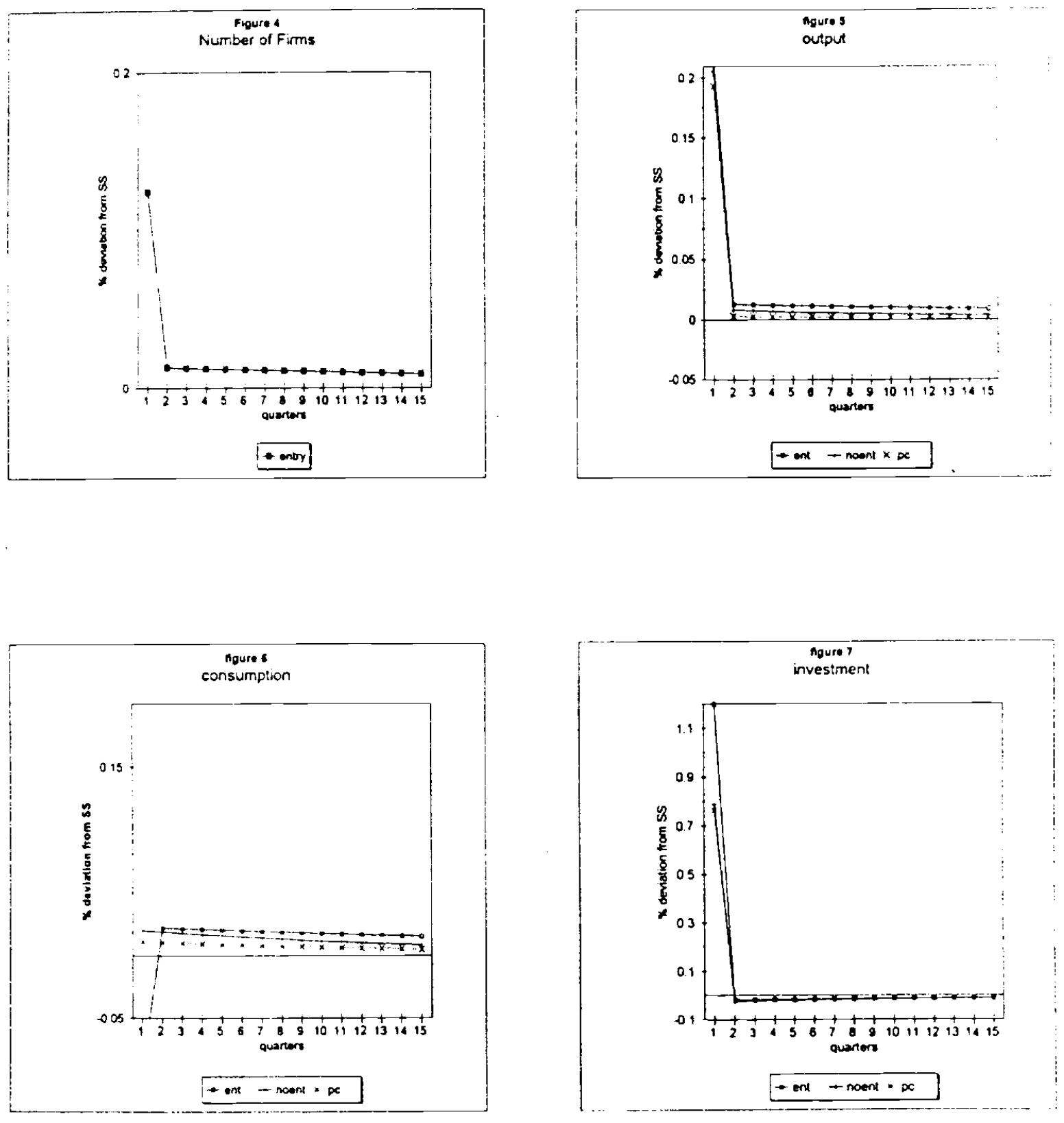

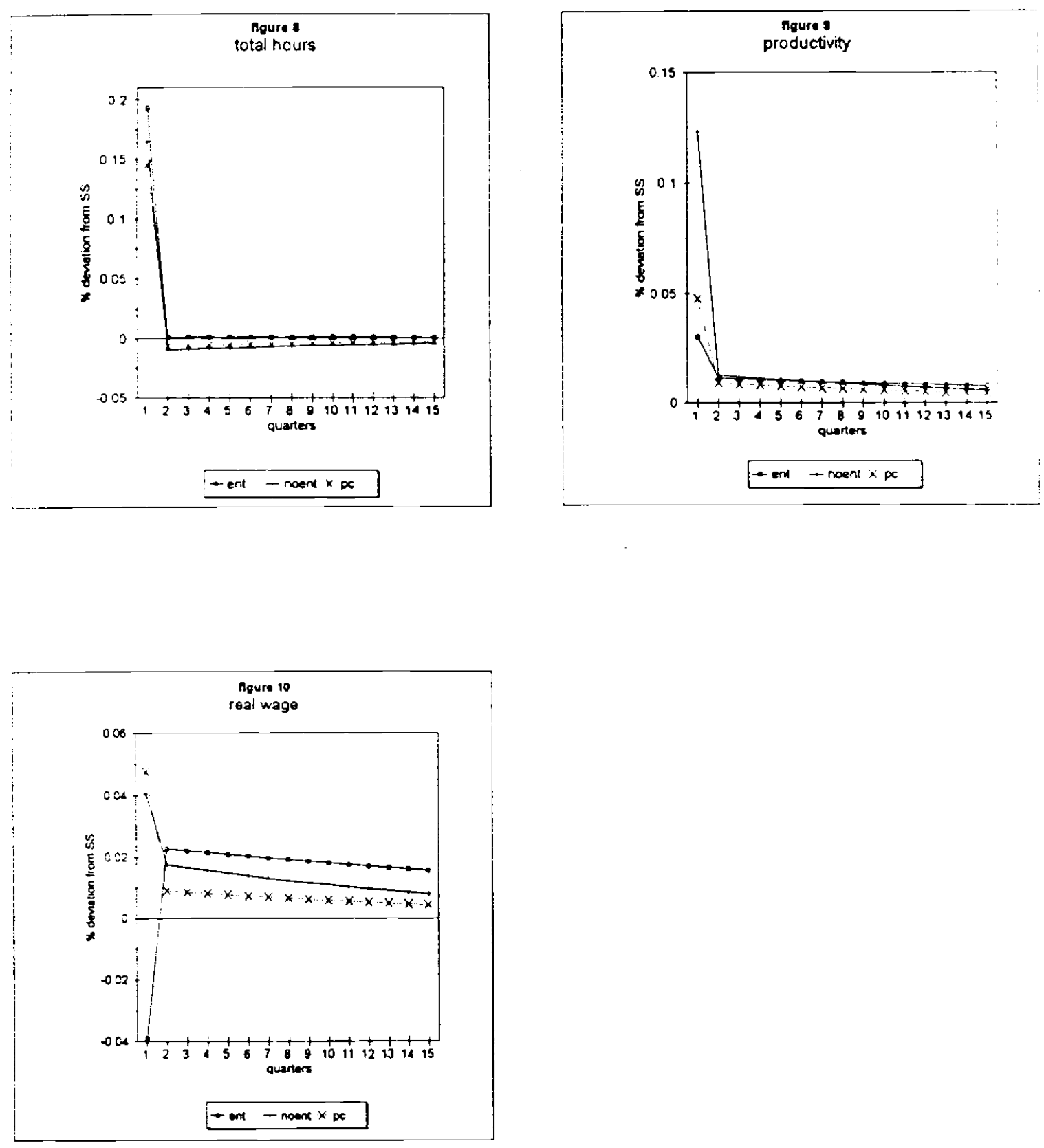
needed to support the elevated number of firms.

A comparison of the dynamic path of real wages and productivity across the three models is also instructive. First, as noted in the previous section, the overhead capital and labor tend to make the marginal productivity of factors more responsive to factor use. As a result, average labor productivity will be more volatile in imperfectly competitive models than in competitive ones. Second, unlike the competitive model, the real wage (the marginal product of labor) does not mirror the behavior of the average productivity of labor. Given the capital stock, an increase in total factor productivity will lead to both the entry of new firms and an increase in the number of workers per firm. This latter effect is sufficiently strong that the marginal product of labor falls at the time of the shock. The average product of labor increases due to the increase in the ratio of production workers to total employment.

Further quantification of these properties are reported in Table 2 where we focus on the standard deviations of aggregate variables, correlations of these variables with respect to output and other properties of the output series. It is important to note that the model with perfect competition has many features that we normally associate with aggregate fluctuations: consumption is less volatile than output, investment is more volatile that output and there are positive contemporaneous correlations between key macroeconomic variables and output. However, as the technology shocks which drive the economy are transitory, there is little serial correlation in output fluctuations.

The addition of monopolistic competition without allowing for entry and exit over the business cycle increases the volatility of consumption and its correlation with output and reduces both the volatility of investment and its correlation with output. More importantly, 
employment fluctuations appear to be dampened by the introduction of monopolistic competition as the standard deviation of hours is reduced by almost $50 \%$. Since the analysis is conducted using an approximation around the steady state, one might think initially that adding in market power through markups would have little impact on the time series properties. Table 2 indicates that this is certainly not the case.

One possible explanation for the effects of market power concerns the method of calibration. The parameters of the Cobb-Douglas technology are inferred from observed factor shares. In this economy, the technological parameters depend on the size of the markup and the relative importance of the overhead inputs. However, when the markups on consumption and investment are 2 and the overhead labor ratio is 1 , as in our economy, then even in the presence of monopolistic competition, labor's share of national income is the same as the exponent on the labor input in the Cobb-Douglas technology. Thus, the effects of monopolistic competition are not due to different estimates of parameters in the CobbDouglas technology. In fact, as explained earlier, the existence of markups implies the presence of overhead labor and capital which dampens the response of firms to variations in the state of technology.

While not described in Table 2, in the no entry treatment, profits of firms are highly procyclical. The entry treatment allows potential entrants to respond to profit opportunities in their participation decisions. The propagation effects of the monopolistically competitive environment with entry and exit are evident from the fact that the serial correlation of output is 11 , about 7 times that produced by the competitive economy. This increased serial correlation comes from the fact that investment is more responsive to technology shocks as 
well the slower transition to the steady state.

One seemingly "odd" feature of the monopolistically competitive economy is the apparent negative correlation between consumption and output. Note that consumption is measured here as the total amount of consumption goods produced, not the consumption index that appears in an agent's utility function. The correlation between output and the consumption index for this treatment is .46 .

Table 3 describes the outcomes of experiments in which the labor supply elasticity is set to $0\left(\xi_{u}=0\right)$ so that intertemporal effects are larger, as in Hansen [1985]. For these treatments, the serial correlation in the technology shock was set at $0(\Phi=0)$. Overall, the increase in the elasticity of labor supply magnifies the response of the economy to shocks in all three treatments. Relative to the results reported in Table 2, increasing the elasticity of labor supply increases the standard deviation of employment from 1.4 to 3.1 under monopolistic competition with entry. Further, the standard deviation of consumption increases from .97 to 2. Finally, there is additional serial correlation in output due to the increased responsiveness of net business formation to the technology shocks. As in the case of the treatments in Table 2, the negative correlation between consumption and output is due to tile fact that this variable represents the total amount of consumption, not the consumption index. As before, the correlation between the consumption index and output is positive.

Table 4 explores variations in the magnitude of the markups in the consumption and investment goods markets. These treatments were undertaken in the case of $\Phi=0$ so that the full effects of intertemporal substitution would be evident. For these variations, we adjust the overhead labor ratio so that the overhead capital ratio and labor's coefficient in the 
technology $(\alpha)$ are reasonable. The values of these variables are reported in the table as well. Other parameters are the same as in the baseline treatment. For these treatments we allow the markups to increase to 3, still within the range estimated by Hall. We also explore asymmetries in markups. ${ }^{20}$

At $v=\theta=3$, we set the overhead labor ratio to 2 as otherwise the overhead capital ratio was 26 and labor's technology coefficient $(\alpha)$ was .96 . Here markups are extremely high so that product variation effects are quite strong. As a consequence, the correlation between the number of firms and output is near one leading to very strong magnification effects. Further, there are persistent variations in the number of products yielding strong propagation effects as well . That is, in this case, the serial correlation in output is .39 .

At the other extreme, when $v=\theta=1.5$, we reduced the overhead labor ratio to .5 as suggested by Davis-Haltiwanger [1991] yielding an overhead capital ratio of .5. In this case, there is some additional persistence through product variation but this effect is much smaller than in the case of $v=\theta=2$. When $v=2$ and $\theta=1$, so that the only product variety effects occur in consumption goods, then there is almost no persistence in output movements.

The set of treatments summarized in Table 5 investigate the effects of serially correlated taste shocks to this economy in the elastic labor supply case. As reported in Baxter-King [1991] as well, the first row of Table 5 indicates the response of consumption and investment to a variation in the marginal rate of substitution between consumption and leisure in the competitive economy. Under perfect competition, we see that investment is

\footnotetext{
30 The case of $v=2$ and $\theta=3$ lead to both eigenvalues being less than one and thus the loss of saddlepath stability. In this case, as in Farmer-Guo [1992], there may be sunspot equilibria. As discussed by Gali [1992] in a model without price discrimination between investment and consumption goods, when $v \neq \theta$ the model has some interesting implications for cyclical variations in the share of investment in output.
} 
negatively correlated with output while consumption is positively correlated with output. This negative correlation between investment and output is also observed in the treatment of monopolistic competition with no entry. However, once entry is introduced, the product space variations become important enough to produce a positive correlation between investment and output, as found in Baxter-King [1991]. ${ }^{21}$ Note further that investment is more volatile than consumption but that productivity is countercyclical..

Finally, we consider the more traditional case of serially correlated technology shocks in Tables $6 \mathrm{a}$ and $6 \mathrm{~b}$ along with related U.S. data. ${ }^{22}$ For Table $6 \mathrm{a}$, the correlations are generated from a model in which the elasticity of the marginal utility of leisure $\left(\xi_{\Perp}\right)$ equals 1. In Table $6 \mathrm{~b}$, the elasticity of the marginal utility of leisure is set at 0 (the discrete employment case) while all other parameters remain unchanged. For all of these treatments, we retain the same standard deviation of the technology shock. ${ }^{23}$

As is well understood, the perfectly competitive real business cycle model does a good job of mimicking the basic pattern of the relative variances found in U.S. data. ${ }^{24}$ Further, as indicated in Table 6a, the basic model produces the serial correlation observed in actual time series, largely due to the fact that in the baseline model the autoregressive coefficient on the technology shock is .9 Finally, the basic correlation pattern is consistent filtered.

21 One must be careful in comparing results as their results pertain to data that was Hodrick-Prescott

2 The U.S. data corresponds with that reported in King, Plosser, Rebelo [1988].

I As argued in Hall [1988] and Hornstein [1992], there is a need to adjust the Solow residual to account for the monopolistic competition. We have not yet made that adjustment as our goal is to document the effects of changes in market structure and not to "match" U.S. data.

24 Basically, due to consumption smoothing in response to technology shocks, consumption is less volatile than output and investment is more volatile. 
with U.S. data except for the correlation of employment with output, which is much too high in the baseline model. ${ }^{25}$

For the case of $\xi_{u}=-1$, both models with monopolistic competition also perform reasonably well. In particular, consumption smoothing is evident and the standard deviation of investment relative to output exceeds 1 in both economies, as in U.S. data. As noted earlier, there is considerable employment dampening due to monopolistic competition and this is a movement toward the observed correlation between output and employment though the standard deviation of employment relative to output is quite low. Once entry and exit is possible, this dampening of employment fluctuations is somewhat offset by allowing product space variations over the cycle. In this sense, product space variations magnify shocks.

We also set $\xi_{\mathrm{u}}=0$ and thus allow for the discrete employment case, see Hansen [1985], in which the representative agent has a more elastic labor supply curve. As expected, relative to Table 6a, the model with monopolistic competition is closer to U.S. data since this change in parameterization increases the relative standard deviation of employment. The correlation of employment with output remains too high and consumption remains too volatile.

Since we have introduced a new channel of interactions into the basic real business cycle model, we should also introduce some new observations. In this regard, we note that for U.S. quarterly data, the correlation between linearly detrended GNP and detrended net business formation is .54 . The corresponding correlation produced in the model with $\xi_{u}=-1$

3 This correlation is also too high for all other parameterizations of labor supply presented in King, Plosser and Rebelo, including the extremes of the inelastic labor supply from labor studies and the infinite elasticity from the discrete employment model. 
is .94 which is a bit high. Once $\xi_{\Perp}=0$, this correlation increases to .96 . Thus the model predicts too much action in net business formation. Further, as the model does not include any idiosyncratic disturbances it is unable to account for any of the widespread heterogeneity observed in the job creation and destruction process described in Davis-Haltiwanger [1990].

One problem in our model is the predicted negative correlation between employment per firm and output when there are correlated technology shocks. For $\xi_{y}=-1$, the predicted correlation between the number of workers per firm and output is -.50. Empirically, adjustments occur in both the intensive and extensive margins in the same basic direction. ${ }^{26}$ This correlation is positive when shocks are temporary but then the model does not generate enough persistence in output. As discussed earlier, at the time of a technology shock, both the number of firms and the number of workers per firm increases along with output. However, the burst in investment activity that occurs at the time of the shock leads to an increase in the capital stock per firm and, through (19), a reduction in workers per firm along the transition path. It is this latter effect which produces the negative correlation between the number of workers per firm and output in our model.

\section{Conclusions}

We first note that the models of monopolistic competition are not obviously inconsistent with observations of U.S. data. In particular, the relative standard deviations are qualitatively consistent and both models exhibit the requisite serial correlation in important

\footnotetext{
36 Using two-digit data on job creation and job destruction supplied by John Haltiwanger, we find that there is a positive correlation between net job creation on the intensive margin (expansions and contractions of existing furns) and net job creation on the extensive margin (births less deaths of tirms) over the 1973-88 period.
} 
aggregate variables.

As predicted by our theory model, we do see that the entry and exit process can create added serial correlation in the data. These effects are particularly pronounced when technology shocks are not very serially correlated since then intertemporal substitution is more active. Further, these effects are more important when labor is more elastically supplied.

One point that bears considerable attention is the nature of the entry/exit process modeled in this paper. In our model, the entry decision was entirely static and did not involve any lags. One extension of the model would be to add a lag in the entry process. ${ }^{27}$ In this way, the immediate response of the economy to variations in technology would be variations in the size of firms but not in their numbers. Over time, the adjustments in the number of firms would arise. In this case, we might be better able to match observations on the interactions between adjustments on the intensive and extensive margins. ${ }^{28}$ Further, one could consider another specification in which there is a fixed cost of entry separate from the fixed costs of production associated with overhead labor and capital. This would add the number of firms as another aggregate state variable to the model and might create additional endogenous persistence as well as a reduced immediate response to shocks.

A further extension of interest would be to introduce more reasonable "demand shocks" into our model. Our results indicate that the model is capable of transforming taste

27 One possibility is to follow Hopenhayn-Rogerson [1991] and assume that potential entrants in period $t$ do not know the realized values of period $t$ shocks.

On this point, we need to further understand the dynamics associated with variations in production and non-production workers in U.S. data. 
shocks into endogenous movements in effective total factor productivity through product space variations, thus magnifying and propagating these shocks. One avenue for further research would be to couple this mechanism for magnification and propagation with other, more interesting, sources of impulses. 


\section{References}

Baxter, M. and R. King, "Productive Externalities and Business Cycles," Institute for Enipirical Macroeconomics, Federal Reserve Bank of Minneapnlis, Discussion Paper \#53, November 1991.

Beaudry, P. and A. Guay, "What Do Interest Rates Reveal about the Functioning of Real Business Cycle Models?" mimeo, Universite de Montreal, December 1992.

Benassy, J.P., "Taste for Variety and Optimum Production Patterns in Monopolistic Competition," CEPREMAP, July 1993.

Benhabib, J. and R. Farmer, "Indeterminacy and Increasing Returns," UCLA Working Paper \#646, January 1992.

Blanchard, O. and S. Fischer, Lectures on Macroeconomics, Cambridge: MIT Press, 1989.

Bryant, J. "A Simple Rational Expectations Keynes-Type Model," Quarterly Joumal of Economics, 97 (1983), 525-29.

Chatterjee, S. and R. Cooper, "Multiplicity of Equilibria and Fluctuations in Dynamic Imperfectly Competitive Economies," American Economic Review: Papers and Proceedings, (1988b).

Chatterjee, S., R. Cooper and B. Ravikumar, "Strategic Complementarity in Business Formation: Aggregate Fluctuations and Sunspot Equilibria, " Review of Economic Studies, 60 (1993), 795-812.

Christiano, L. and M. Eichenbaum, "Current Real Business Cycle Theories and Aggregate Labor Market Fluctuations," American Economic Review, 82 (1992), 430-50.

Ciccone, A. and R. Hall, "Productivity and the Density of Economic Activity," NBER Working Paper \#4313, April 1993.

Cooper, R. and J. Haltiwanger, "Automobiles and the National Industrial Recovery Act: Evidence on Industry Complementarities, " Quarterly Journal of Economics, 108 (1993), 1043-71.

Davis, S. and J. Haltiwanger, "Gross Job Creation, Gross Job Destruction and Employment Reallocation," Quarterly Joumal of Economics, 107 (1992), 819-64.

, "Gross Job Creation and Destruction: Microeconomic Evidence and Macroeconomic Implications," NBER Macroeconomics Annual, 1990, 123-186. 
,"Wage Dispersion Between and Within U.S. Manufacturing Plants, 1963-1986," Brookings Papers: Microeconomics, 1991, 115-200.

Devereux, M., A. Head and B. Lapham, "Exit and Entry, Increasing Returns to Specialization and Business Cycles, " mimeo, University of British Columbia, October 1992.

Dixit, A. and J. Stiglitz, "Monopolistic Competition and Optimum Product Diversity," American Economic Review, 67 (1977), 297-308.

Domowitz,I., G. Hubbard and B. Peterson, "Market Structure and Cyclical Fluctuations in U.S. Manufacturing," Review of Economics and Statistics, 70 (1988), 55-66.

Farmer, R. and J.T. Guo, "Real Business Cycles and the Animal Spirits Hypothesis," mimeo, UCLA, October 1992.

Galeotti, M and F. Schiantarelii, "Variable Markups in a Model with Adjustment Costs: Econometric Evidence for U.S. Industry," mimeo, Boston University, July 1991.

Gali, J. "Monopolistic Competition, Business Cycles, and the Composition of Aggregate Demand," mimeo, Columbia University, August 1992, forthcoming Journal of Economic Theory.

"Product Diversity, Endogenous Markups and Development Traps," mimeo, Columbia University, June 1993.

Hall, R. "The Relation Between Price and Marginal Cost in U.S. Industry, " Journal of Political Economy, 96 (1988), 921-47.

Hall, R. "Invariance Properties of Solow's Productivity Residual," NBER Working Paper $\# 3034,1989$.

Hammour, M., "Overhead Costs and Economic Fluctuations," mimeo, Columbia University, May 1991.

Hansen, G. "Indivisible Labor and the Business Cycle," Journal of Monetary Economics, 16 (1985), 309-27.

Hopenhayn, H. and R. Rogerson, "Job Turnover and Policy Evaluation in a Model of Industry Equilibrium," mimeo, Stanford University, 1991.

Hornstein, A., "Monopolistic Competition, Increasing Returns to Scale and the Importance of Productivity Shocks," mimeo, University of Western Ontario, 1992. 
Jovanovic, B. "The Diversification of Production," Brookings Papers: Microeconomics, (1993), 197-247.

King, R., C. Plosser and S. Rebelo, "Production, Growth and Business Cycles: I. The Basic Neoclassical Model, " Lournal of Monetary Economics, 21 (1988), 195-232.

Kiyotaki, N. "Multiple Expectational Equilibria under Monopolistic Competition," Quarterly Journal of Economics, 103 (1988), 695-714.

Klenow, P., "Externalities and Economic Fluctuations," mimeo, Stanford University, 1990.

Murphy, K., Shleifer, A. and R. Vishny, "Building Blocks of Market Clearing Business Cycle Models," in NBER Macroeconomics Annual, 1989, ed. by O. Blanchard and S. Fisher.

Rotemberg, J. and G. Saloner, "A Supergame-Theoretic Model of Price Wars during Booms," American Economic Review, 76 (1986), 390-407.

Rotemberg, J. and M. Woodford, "Markups and the Business Cycle," paper presented at the NBER Sixth Annual Conference on Macroeconomics, March 1991.

Working Paper \# 3534, December 1990.

, "Cyclical Markups: Theory and Evidence," NBER , "Oligopolistic Pricing and the Effects of Aggregate Demand on Economic Activity," Joumal of Political Economy, 100 (1992), 1153 1207.

Shea, J., "Complementarities and Comovements" mimeo, University of Wisconsin, 1993.

Stokey, N. "Learning by Doing and the Introduction of New Goods," Journal of Political Economy, 96 (1988), 701-717.

U.S. Department of Commerce, Historical Statistics of the United States, Washington: USGPO, 1975 
Table 1

Baseline Parameter Values

\begin{tabular}{|l|c|c|c|}
\hline \multicolumn{1}{|c|}{ TREATMENT } & $\nu$ & $\theta$ & $\begin{array}{c}\text { overhead } \\
\text { labor ratio }\end{array}$ \\
\hline BASELINE & 1 & 1 & 0 \\
\hline $\begin{array}{l}\text { Mono. Comp } \\
\text { no entry }\end{array}$ & 2 & 2 & 1 \\
\hline $\begin{array}{l}\text { Mono. Comp. } \\
\text { with entry }\end{array}$ & 2 & 2 & 1 \\
\hline
\end{tabular}

Table 2

Experiments with Zero Serial Correlation in Technology Shock $(\Phi=0)$

\begin{tabular}{||l|c|c|c|c|c|c|c|c|c|c|}
\hline \hline TREATMENT & \multicolumn{4}{|c|}{$\begin{array}{c}\text { Corr. with Y } \\
\text { Contemporaneous }\end{array}$} & \multicolumn{5}{c|}{ Standard Deviation } & \multicolumn{2}{c|}{ Statistics for Y } \\
\hline & $\mathrm{C}$ & Hrs & Inv & Prod & C & Hrs & Inv & Prod & sd $^{*}$ & sc \\
\hline \hline Perf. Comp. & .36 & .98 & .99 & .88 & .26 & 1.1 & 5.75 & .42 & 1.45 & .017 \\
\hline $\begin{array}{l}\text { Mono. Comp. } \\
\text { No Entry }\end{array}$ & .44 & .96 & .98 & .98 & .45 & .63 & 5.94 & .97 & 1.55 & .05 \\
\hline $\begin{array}{l}\text { Mono. Comp. } \\
\text { With Entry }\end{array}$ &. .48 & .98 & .95 & .72 & .97 & 1.4 & 9.02 & .43 & 1.73 & .11 \\
\hline
\end{tabular}

- Actual standard deviations $\times 10^{2}$ 
Table 3

Experiments with Elastic Labor Supply: $\left(\xi_{u}=0, \Phi=0\right)$

\begin{tabular}{|c|c|c|c|c|c|c|c|c|c|c|}
\hline \multirow[t]{2}{*}{ TREATMENT } & \multicolumn{4}{|c|}{$\begin{array}{l}\text { Corr. with Y } \\
\text { Contemporaneous }\end{array}$} & \multicolumn{4}{|c|}{ Standard Deviation" } & \multicolumn{2}{|c|}{ Statistics for $Y$} \\
\hline & C & Hrs & Inv & Prod & C & Hrs & Inv & Prod & sd & $\begin{array}{l}\text { serial } \\
\text { corr. }\end{array}$ \\
\hline Perf. Comp. & .36 & .99 & .99 & .36 & .31 & 1.81 & 7.5 & .31 & 1.9 & .018 \\
\hline $\begin{array}{l}\text { Mono. Comp. } \\
\text { No Entry }\end{array}$ & .43 & .96 & .98 & .97 & .49 & .82 & 6.9 & 1.0 & 1.8 & .042 \\
\hline $\begin{array}{l}\text { Mono. Comp. } \\
\text { Entry }\end{array}$ & -.54 & .97 & .94 & -.23 & 2.0 & 3.1 & 16.1 & .7 & 2.9 & .13 \\
\hline
\end{tabular}

- Actual standard deviations x $10^{2}$

Table 4

Experiments with Altemative Markups

Monopolistic Competition with Entry: $\left(\xi_{u}=-1, \Phi=0\right)$

\begin{tabular}{|c|c|c|c|c|c|c|c|c|c|c|}
\hline \multirow[t]{2}{*}{ TREATMENT } & \multicolumn{4}{|c|}{$\begin{array}{l}\text { Corr. with Y } \\
\text { Contemporaneous }\end{array}$} & \multicolumn{4}{|c|}{ Standard Deviation" } & \multicolumn{2}{|c|}{$\begin{array}{l}\text { Statistics } \\
\text { for } Y\end{array}$} \\
\hline & C & Hrs & Inv & Prod & C & Hrs & Inv & Prod & $\mathbf{s d}^{*}$ & sc \\
\hline $\begin{array}{l}\nu=2, \theta=2, \\
\alpha=.64, \text { nover }=1, \\
\text { kover }=1\end{array}$ & -.48 & .98 & .95 & .72 & .97 & 1.4 & 9.02 & .43 & 1.73 & .11 \\
\hline $\begin{array}{l}v=3, \theta=3, \\
\alpha=.64, \text { nover }=2, \\
\text { kover }=2\end{array}$ & -.04 & .96 & .77 & .71 & 2.55 & 1.8 & 12.5 & .74 & 2.3 & .391 \\
\hline $\begin{array}{l}u=1.5, \theta=1.5, \\
\alpha=.64 \\
\text { nover }=.5, \text { kover }=.5\end{array}$ & -.40 & .98 & .98 & .28 & .5 & 1.3 & 7.3 & .41 & 1.6 & .05 \\
\hline $\begin{array}{l}\nu=2, \theta=1, \alpha=.69 \\
\text { nover }=.5 \\
\text { kover }=.85\end{array}$ & .39 & .99 & .99 & .96 & .3 & 1.0 & 5.8 & .46 & 1.5 & .01 \\
\hline
\end{tabular}

- Actual standard deviations $\times 10^{2}$ 
Table 5

Preference Shocks: $B_{1+1}=0.9 B_{1}+e_{4} E(e)=0, \operatorname{Var}(e)=0.0072^{2}, \xi_{u}=0$

\begin{tabular}{|l|c|c|c|c|c|c|c|c|c|c||}
\hline & \multicolumn{4}{|c|}{$\begin{array}{c}\text { Corr. with Y } \\
\text { Contemporaneous }\end{array}$} & \multicolumn{3}{c|}{$\begin{array}{c}\text { Standard Deviation Relative } \\
\text { to } Y\end{array}$} & \multicolumn{3}{c|}{$\begin{array}{c}\text { Statistics for } \\
Y\end{array}$} \\
\hline & C & Emp & Inv & Prod & C & Emp & Inv & Prod & sd & sc \\
\hline \hline Perf. Comp. & .99 & .99 & -0.94 & -0.96 & 0.99 & 1.70 & 1.39 & 0.72 & .0071 & .900 \\
\hline $\begin{array}{l}\text { Mono Comp } \\
\text { No Entry }\end{array}$ & .99 & .99 & -0.96 & .78 & 1.57 & .21 & 0.83 & .19 & .0075 & .88 \\
\hline $\begin{array}{l}\text { Mono Comp } \\
\text { with Entry }\end{array}$ & .95 & .95 & .79 & -0.37 & .99 & 1.21 & 1.49 & .42 & .013 & .944 \\
\hline
\end{tabular}


Table $6 \mathrm{a}$

Serially Correlated Technology Shocks and U.S. Data $\xi_{4}=-1$

\begin{tabular}{|l|c|c|c|c|c|c|c|c|c|c||}
\hline TREATMENT & \multicolumn{3}{|c|}{$\begin{array}{c}\text { Corr. with Y } \\
\text { Contemporaneous }\end{array}$} & \multicolumn{3}{c|}{$\begin{array}{c}\text { Standard Deviation } \\
\text { Relative to Y }\end{array}$} & \multicolumn{2}{c|}{$\begin{array}{c}\text { Statistics for } \\
\text { Y }\end{array}$} \\
\hline & C & Emp & Inv & Prod & C & Emp & Inv & Prod & sd & $\begin{array}{l}\text { serial } \\
\text { corr. }\end{array}$ \\
\hline & .80 & .81 & .91 & .90 & .62 & .50 & 2.82 & .67 & .032 & .92 \\
\hline $\begin{array}{l}\text { Perf. Comp. } \\
\text { Mono.Comp. } \\
\text { No Entry }\end{array}$ & .91 & .57 & .85 & .99 & .83 & .18 & 2.05 & .91 & .031 & .93 \\
\hline $\begin{array}{l}\text { Mono. Comp. } \\
\text { With Entry }\end{array}$ & .85 & .96 & .80 & .98 & .84 & .38 & 2.35 & .64 & .035 & .95 \\
\hline $\begin{array}{l}\text { U.S. Data } \\
\text { (Quarterly) }\end{array}$ & .85 & .07 & .6 & .76 & .69 & .52 & 1.35 & 1.14 & .056 & .96 \\
\hline
\end{tabular}

Table 6b

Serially Correlated Technology Shocks and U.S. Data: Elastic Labor Supply $\xi_{u}=0$

\begin{tabular}{||l|c|c|c|c|c|c|c|c|c|c||}
\hline TREATMENT & \multicolumn{4}{|c|}{$\begin{array}{c}\text { Corr. with Y } \\
\text { Contemporaneous }\end{array}$} & \multicolumn{3}{c|}{$\begin{array}{c}\text { Standard Deviation } \\
\text { Relative to Y }\end{array}$} & \multicolumn{3}{c|}{$\begin{array}{c}\text { Statistics for } \\
\text { Y }\end{array}$} \\
\hline & C & Emp & Inv & Prod & C & Emp & Inv & Prod & sd & $\begin{array}{c}\text { serial } \\
\text { corr. }\end{array}$ \\
\hline \hline Perf. Comp. & .78 & .83 & .92 & .78 & .58 & .65 & 2.94 & .58 & .037 & .906 \\
\hline $\begin{array}{l}\text { Mono.Comp. } \\
\text { No Entry }\end{array}$ & .91 & .60 & .86 & .98 & .82 & .21 & 2.11 & .89 & .033 & .927 \\
\hline $\begin{array}{l}\text { Mono. Comp. } \\
\text { With Entry }\end{array}$ & .84 & .95 & .78 & .97 & .86 & .48 & 2.39 & .56 & .042 & .953 \\
\hline $\begin{array}{l}\text { U.S. Data } \\
\text { (Quarterly) }\end{array}$ & .85 & .07 & .6 & .76 & .69 & .52 & 1.35 & 1.14 & .056 & .96 \\
\hline
\end{tabular}

